\title{
Antecipação de colocações - uma estratégia para a interpretação simultânea do alemão para o português
}

Julia de Gouvêa e Silva Hellmuth*

\section{Introdução}

A competência linguística em um idioma vai além de conhecer bem suas regras gramaticais; ela implica também um conhecimento profundo das regras particulares de combinação de termos e, sobretudo, do significado resultante de grupos de palavras combinadas, os chamados fraseologismos ${ }^{1}$.

Cada língua lança mão de um escopo diferente de combinações de palavras. Por essa razão, tradutores e intérpretes têm de estar atentos à ocorrência dessas expressões, a fim de evitar erros interpretativos, quer na interpretação para a língua nativa, quer para a língua estrangeira. Para intérpretes com o par de idiomas alemão-português, as colocações são ainda mais importantes, porque podem ser usadas como estratégia prática para antecipar os verbos principais que comumente aparecem no fim da frase em alemão.

Ainda não há uma única definição clara e aceita por todos os linguistas para o conceito de colocação, mas os estudos atuais no campo das colocações alemãs baseiam-se nas ideias desenvolvidas pelo romanista e lexicólogo alemão Franz Josef Hausmann, cujas definições são a base de análise das colocações do presente artigo.

\footnotetext{
* Julia de Gouvêa e Silva Hellmuth é tradutora e intérprete e mestre em Interpretação de Conferências alemão-português-inglês pela Universidade de Heidelberg, onde lecionou tradução e interpreetação simultânea e consecutiva de 2011 a 2013. Este artigo é inspirado em partes de sua dissertação de Mestrado (Universidade de Heidelberg, 2011).

${ }^{1} \mathrm{O}$ fraseologismo é o objeto de estudo da Fraseologia, subdisciplina da Lexicologia, sendo as colocações um tipo de fraseologismo.
} 


\title{
2. Colocações segundo Hausmann
}

Hausmann (apud Mohr, 2009) observou que, enquanto alguns termos de um idioma são combináveis com praticamente quaisquer outros, há um determinado grupo que apresenta um grau de combinabilidade bem restrito, associando-se apenas a um número bem pequeno de palavras. Tal fenômeno não se deve a regras semânticas ou gramaticais, mas a uma afinidade entre os termos a serem combinados ou, nas palavras de Hausmann, "a uma tendência de duas palavras aparecerem combinadas" (apud Mohr, 2009, p. 9).

Hausmann escreve (tradução nossa):

\begin{abstract}
"Combinações afins (...) são produtos semi-prontos da língua, que o falante não combina de forma criativa, e sim formula como um todo a partir da memória, e que o ouvinte reconhece. Chamaremos esse tipo de combinações afins de colocações."2
\end{abstract}

Como complementa Holderbaum (2003, p. 14), as colocações são combinações típicas, específicas e características de duas palavras, "cujos componentes se relacionam de forma essencial" - como, por exemplo, atear e fogo, mas diferentemente dos termos ver e objeto. Em português, o verbo atear é proferido quase exclusivamente com o substantivo fogo, salvo licenças poéticas, ao passo que ver pode ser combinado com praticamente qualquer substantivo da língua.

O repertório de colocações na memória do falante se forma à medida que ele se expõe a determinada língua. Se nativo da língua portuguesa, por exemplo, ele saberá que o verbo que se combina à palavra passo é dar, resultando em dar um passo, e não fazer, como einen Schritt tun ("fazer um passo"), em alemão. Essas combinações se consolidam arbitrariamente na língua, o que fica bem claro ao se estudar outros idiomas e se perceber que as combinações que se conhecem na língua materna não se aplicam a outros idiomas.

\footnotetext{
${ }^{2}$ Affine Kombinationen (...) sind Halbfertigprodukte der Sprache, welche der Sprecher nicht kreativ zusammensetzt, sondern als Ganzes aus der Erinnerung holt und der Hörer als bekannt empfindet. Wir wollen diesen Typ der affinen Kombination 'Kollokation' nennen. (Hausman, apud Mohr, 2009, p. 9)
} 
O cerne da questão nesse aspecto é definir quais são os componentes que de fato co-ocorrem, ou seja, que têm afinidade entre si e são "fixos", e quais são apenas uma soma de duas ideias reunidas.

Hausmann dividiu as combinações de palavras (Wortverbindung) em dois grupos: as combinações fixas (fixiert) e as não fixas (nicht fixiert). As combinações fixas referem-se a provérbios e expressões idiomáticas, como "pôr os pingos nos is" ou "dar uma mãozinha", enquanto que as não fixas dividem-se entre as colocações (affin) e duas outras categorias, chamadas co-criações (frei) e contra-criações (konter-affin). No presente artigo vamos nos ocupar somente das combinações afins, ou seja, as colocações.

\subsection{Relação Base x Colocador}

Os termos integrantes das colocações desempenham duas funções diferentes. Hausmann definiu esses componentes como base e colocador, explicando que sua relação é hierárquica. A base é autônoma e pode ser definida mesmo sem um contexto semântico. Ela é a unidade superior, sendo o ponto de partida para a combinação. O colocador, por sua vez, tem como função caracterizar e descrever a base e assume também um significado definido somente após ser combinado com a base. $\mathrm{O}$ verbo travar, por exemplo, adota acepções completamente diferentes quando combinado com os termos porta ou guerra. Porta ou guerra são a base autônoma e o verbo travar é o colocador. Se combinado com porta, travar significa bloquear, obstruir; se combinado com guerra, significa iniciar, acontecer. Como se pode verificar, a base é semanticamente independente, enquanto o colocador tem de se adequar a ela.

Hausmann diferencia seis tipos de colocações características do alemão, de acordo com as categorias gramaticais de seus integrantes, dos quais apenas dois são relevantes para a tradução para a língua portuguesa:

$$
\begin{array}{ll}
\text { substantivo (objeto) + verbo } & \text { Ein Urteil fällen ("Proferir uma sentença") } \\
\text { substantivo (sujeito) + verbo } & \text { Der Ausschuss tagt ("O comitê reúne-se") }
\end{array}
$$


Na língua portuguesa, o modelo estrutural é diferente do alemão e semelhante ao do francês, também desenvolvido por Hausmann e adaptado por Bernhard Pöll (Pöll, 1996, p. 21). Nesse caso, somente o tipo abaixo é interessante para a análise do presente artigo.

$$
\text { verbo + substantivo Chamar a atenção }
$$

Em alemão, a base Urteil ("sentença") é frequentemente acompanhada do verbo fällen ("proferir"), como em português usamos o verbo "chamar" para a base "atenção", ou "atear" para a base "fogo".

Em um idioma como o alemão, em que o verbo principal aparece frequentemente no fim da oração, conhecer essas combinações de termos é muito importante para saber prever que colocador será enunciado.

\section{Antecipação: estratégia de interpretação simultânea}

Wörrlein explica em sua obra de 2007, Der Simultandolmetschprozess: eine empirische Untersuchung, que as estratégias de interpretação são desenvolvidas ou descritas com o intuito de trazer à consciência dos intérpretes formas que facilitem a execução da atividade interpretativa que se desenrola em suas mentes, capacitando-os assim a lançar mão de ferramentas de modo automático e deliberado. O intérprete passa a conhecer os riscos de cada estratégia e aprende a contorná-los, resultando assim no domínio do que chamamos hoje de "técnicas de interpretação" (Wörrlein, 2007, p. 27). A antecipação, objeto de estudo do presente trabalho, é apenas uma das estratégias existentes.

"Antecipar" significa "prever" algo que irá acontecer. $\mathrm{Na}$ interpretação, antecipar significa prever o que o orador vai dizer ou como irá concluir uma frase. Essa é uma estratégia bastante importante na interpretação simultânea, pois auxilia o intérprete a tornar seu texto-alvo mais fluente e evita possíveis hesitações.

Consideremos a seguinte frase em alemão: 
Dieses Thema wird bei unserem nächsten Treffen, das sich in die Reihe unser bisherigen Verhandlungen anschließt und bei dem wir einem abschließenden Konsens kommen wollen, erneut auf der Tagesordnung stehen. ${ }^{3}$

Em tradução literal nossa, o equivalente em português seria: "Esse tema vai no nosso próximo encontro, que se junta à série das nossas negociações e para as quais pretendemos chegar a um consenso final, estar novamente presente na pauta." Se um intérprete que está traduzindo para o português se depara com a frase em alemão acima, ele tem de ser capaz de antecipar o que o orador vai dizer, ou será obrigado a fazer uma pausa bastante longa até ouvir as 5 últimas palavras do enunciado e entender seu significado. A outra opção seria formular uma frase sintaticamente impossível ou, no mínimo, incomum aos ouvidos dos falantes nativos da língua-alvo, como na tradução literal acima, pois o português não permite esse tipo de construção, em que o verbo aparece somente no final da frase.

A antecipação de fragmentos de frase é um dos processos estratégicos mais básicos da interpretação. Para Barbara Moser (Sánchez Martínez, 1988), esse é um processo natural mesmo na comunicação monolíngue cotidiana. Não são raras as vezes em que o interlocutor "adivinha" o que o orador vai dizer e completa a frase antes que este o faça.

Não obstante, os fragmentos de texto a serem proferidos só podem ser antecipados depois de a frase já ter sido iniciada e alguns elementos terem servido como pistas para sua conclusão. Essas pistas podem ser sintáticas e/ou semânticas ou podem depender do conhecimento de mundo ou de determinado assunto por parte do intérprete.

Kalina (1998) categoriza os processos estratégicos conforme auxiliem na recepção do texto-fonte (compreensão) ou na produção do texto-alvo. A antecipação é uma estratégia que integra ambas as categorias, pois ela permite ao intérprete entender o texto de forma mais célere, ajudando-o dessa forma a produzir um enunciado de maneira mais natural e sem hesitações ou pausas.

\footnotetext{
${ }^{3}$ Exemplo retirado do trabalho de Roland Mohr (Mohr, 2009, p. 81).
} 
Há duas formas de antecipação postuladas por Gile (1995) e Kalina (1998). O que Gile chama de "antecipação linguística", Kalina denomina antecipação bottom-up, posto que o intérprete é capaz de prever termos do enunciado da língua fonte a partir de sua estrutura linguística. Para tanto, é preciso recorrer à memória de longo prazo e aos conhecimentos armazenados a respeito da língua, incluindo conhecimentos sintáticos e semânticos.

Wörrlein (2007) ainda ressalta o importante papel da sintaxe de um idioma, que é fixado por regras específicas, de forma que palavras de classes gramaticais diferentes não são distribuídas aleatoriamente em uma frase. Por meio desse conhecimento de regras a que o intérprete muitas vezes recorre de forma inconsciente, ele é capaz de captar pistas sintáticas de como será a continuação da oração. Ele o faz gerando hipóteses de probabilidade do que poderá vir a ser proferido. Quanto mais pistas houver, maior será sua chance de antecipar corretamente.

A pesquisadora não esquece de apontar para o fato de que a antecipação não significa necessariamente prever de forma exata a escolha vocabular do orador, mas sim o conteúdo de fragmentos da informação a ser transmitida. Se o intérprete realmente tiver a habilidade de antecipar o orador, ele poderá interpretar na língua-alvo mesmo antes de ouvir determinadas palavras.

Mas é o conhecimento semântico que possibilita ao intérprete prever colocações. Assim que o intérprete ouve um elemento da colocação, sobretudo se for a base, ele pode automaticamente completar com o segundo elemento, o colocador. E dessa forma, pode se concentrar na próxima frase a ser enunciada. A interpretação, neste caso, poderia ocorrer de fato simultaneamente ou até mesmo antes do orador concluir seu enunciado.

Esse aspecto é importante em especial no caso da interpretação de línguas germânicas para línguas latinas, como o português. Como a estrutura do alemão requer, em determinados casos, que o verbo principal seja posicionado no fim da frase, algo não permitido nas línguas latinas, é necessário ao intérprete antecipar o verbo para formar uma frase fluente e idiomática na língua latina. 
Isso é válido tanto para colocações, como para conjunções e pares, como não só... como também ou nem... nem. Ao ouvir não só, o intérprete já pode dizer como também mesmo antes de ouvi-lo.

A segunda forma de antecipação postulada por Gile é a "antecipação linguística e extralinguística". Em 1988, Sánchez Martínez elaborou uma análise sobre o trabalho de Barbara Moser, Simultaneous Interpretation: a Hypothetical Model and its Practical Application, onde apresentou casos desse tipo de antecipação em situações reais do alemão para o espanhol. O exemplo abaixo ilustra muito bem uma situação em que os dois tipos de antecipação ajudam-se mutuamente para a produção da interpretação. Embora o exemplo seja em espanhol, pode-se aplicá-lo ao português devido à grande semelhança entre as estruturas sintáticas dos dois idiomas. Em letras maiúsculas está o discurso do orador e em letras minúsculas, em azul, a interpretação simultânea.

\section{HEUTE GEHT IN WASHINGTON DAS GIPFELTREFFEN ZWISCHEN PRÄSIDENT REAGAN UND GENERALSEKRETÄR GORBATSCHOW}

\section{Hoy termina en Washington}

\section{ZU ENDE.}

la cumbre entre el presidente norteamericano Reagan y el secretario general Gorbachov.

O intérprete foi capaz de antecipar o sintagma verbal zu Ende gehen ("terminar", "chegar ao fim") em alemão, porque ele estava inserido no contexto e tinha conhecimento de que aquele era o último dia da cúpula. Ao ouvir o verbo gehen ("geht"), ele facilmente pôde antecipar o verbo em espanhol terminar, formulando uma frase sintaticamente perfeita.

\section{Antecipação e colocações}

Esta seção se debruça sobre a análise contrastiva das estruturas sintáticas do português e do alemão e suas implicações no processo interpretativo para os profissionais que trabalham com esse par de idiomas. 


\subsection{Português}

O português, assim com as outras línguas latinas, apresenta, via de regra, uma ordem frásica de palavras do tipo SVO (sujeito + verbo + objeto), isto é, de "ordem direta" (Franco, 2011). A categoria "objeto" refere-se tanto ao objeto direto quanto ao indireto. Os advérbios apresentam certa flexibilidade no idioma e podem ser encontrados em diferentes posições.

Exemplos claros de orações diretas são:

a) Marta penteia o cabelo hoje.

b) O diretor da escola gostou da nova metodologia.

A língua portuguesa também permite, por questões estilísticas, prosódicas ou de ênfase, outras ordens frasais, como:

c) Caberá a ela a responsabilidade?

VOS

d) O presente enviamos nós.

OVS

Endruschat (2006, p. 119) lista ainda duas outras possibilidades de ordem sintática no português (VSO e OSV) e mais duas em que o sujeito encontra-se oculto (VO e OV). Cabe frisar que as orações (c) e (d) acima também estariam corretas se estivessem formuladas na ordem direta.

As frases supracitadas contêm somente um elemento como verbo. No entanto, sua configuração não muda significativamente se passarmos a ter uma locução verbal de mais de um elemento, como exemplificam as frases retiradas de Franco (2011, p. 183):

e) Não tínhamos até o momento descoberto a avaria na máquina.

f) Nos últimos anos o nosso departamento de desporto tem crescido a olhos vistos.

Essas frases demonstram que as locuções verbais até permitem o posicionamento de um advérbio entre seus dois elementos (o verbo auxiliar e o verbo principal), mas, diferentemente do alemão, como veremos na 
próxima seção, o segundo verbo, o verbo principal, não ocupa necessariamente a última posição da frase.

\subsection{Alemão}

O alemão, por sua vez, não permite a flexibilidade do português. "Die Wortfolge im Deutschen ist streng", ou seja, "A ordem das palavras em alemão é rígida" (Rall, Engel \& Rall, 1985, p. 12). As frases assertivas constituídas por apenas um elemento verbal também costumam ser de ordem direta, como nas frases:

g) Bettina isst Eis. ("Bettina está tomando sorvete") SVO

h) Der Hund jagt die Katze. ("O cão caça o gato") SVO

É possível também mudar a ordem do $\mathrm{S}$ e do $\mathrm{O}$, desde que o verbo se mantenha na segunda posição (Die Katze jagt der Hund - que, diferentemente do português, mesmo trocando a ordem dos elementos na frase, continua significando "o cão caça o gato", já que o artigo de Hund continua com declinação de nominativo, e não de acusativo). António Franco (2011) descreve com precisão uma regra fixa da língua alemã a respeito da ordem dos elementos frásicos:

\footnotetext{
[...] o verbo é o elemento em torno do qual se posicionam os actantes e os adjuntos; e se um qualquer destes ocupar a primeira posição sintáctica, o ante-campo, isso implica automaticamente que todos os restantes elementos ocupem uma posição à direita do verbo finito ${ }^{4}$ (Franco, p. 181).
}

Com essa descrição e a alusão ao verbo finito, Franco já dá uma pista da estrutura frásica um tanto idiossincrática da língua alemã quando contém locuções verbais, como é o caso das formas compostas do passado, os chamados Perfekt e Plusquamperfekt - com o verbo auxiliar e o verbo principal no particípio (haben/hatten + gemacht) -, ou do futuro (werden + verbo principal), ou quando a oração é constituída de um verbo modal (por exemplo, müssen e sollen) e um verbo principal.

\footnotetext{
${ }^{4}$ Verbos finitos referem-se aos verbos auxiliares e modais, ou seja, se opõem aos verbos principais.
} 
No alemão, diferentemente do português, quando o verbo constitui uma locução verbal, no caso de frases assertivas, o verbo principal têm de aparecer necessariamente no final da frase, e o verbo finito (modais e auxiliares) aparece, via de regra, na segunda posição da frase.

Franco e Rall, Engel \& Rall (1985) oferecem esquemas gráficos nos quais certos símbolos representam elementos frásicos e proporcionam uma ilustração visual da estrutura frásica alemã. A seguir, uma apresentação resumida dos esquemas:

\section{Símbolos}

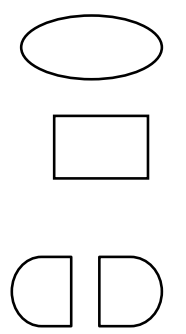

Verbo

Elementos frásicos não classificados (sujeitos, objetos ou locuções adverbiais)

Locução verbal: $1^{\mathrm{a}}$ metade $=$ parte finita, $2^{\mathrm{a}}$ metade $=$ parte infinita

Figura 1: Símbolos de estrutura sintática (Rall, Engel \& Rall, 1985)

Nesse esquema, uma oração assertiva com apenas um elemento verbal é representada da seguinte forma:

Verbo
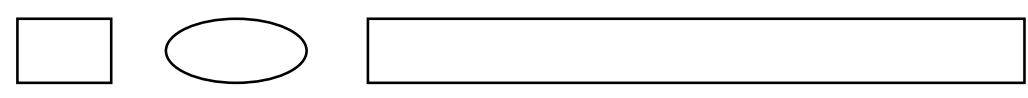

Petra machte ihre Hausaufgaben im Wohnzimmer.

("Petra fazia seus deveres de casa na sala") 
Abaixo, uma oração assertiva com uma locução verbal:

$\mathrm{V} 1$
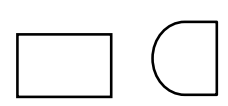

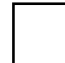

Petra hat ihre Hausaufgaben im Wohnzimmer gemacht.

("Petra fez seus deveres de casa na sala")

Se deslocarmos o sujeito Petra para depois do V1, algum outro elemento, seja ihre Hausaufgaben ou im Wohnzimmer, tem de ser inserido antes de V1, pois o verbo finito tem de estar sempre na segunda posição da frase, assim:

Ihre Hausaufgaben hat Petra im Wohnzimmer gemacht.

Im Wohnzimmer hat Petra ihre Hausaufgaben gemacht.

Há ainda mais um caso complexo que obriga os verbos a aparecerem no fim da frase alemã: as orações subordinadas iniciadas por conjunções, como weil, ob, dass e obwohl (respectivamente "porque", "se", "que" e "embora"), para citar apenas algumas. Nesse caso, tanto um único verbo quanto uma locução verbal são "empurrados" para o fim da frase: 
Caso 1

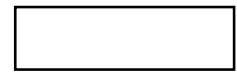

Ich weiss nicht, ob Petra heute kommt.

("Eu não sei se Petra hoje vem")
V

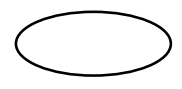

Caso 2

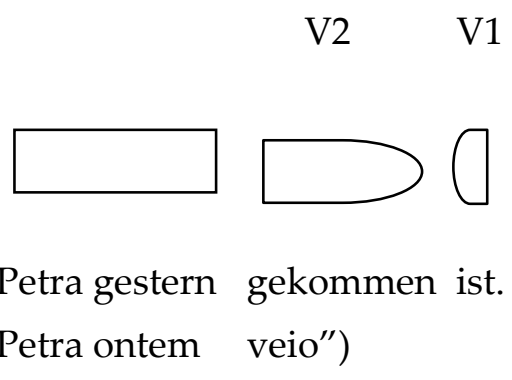

4.3 Antecipação de colocações

Como vimos nas duas seções precedentes, as estruturas sintáticas do alemão e do português contêm diferenças bem marcantes. Enquanto no alemão alguns elementos linguísticos, como certas conjunções ou locuções verbais, exigem a colocação do verbo principal no final da frase, no português, ordens frásicas como $\mathrm{SV}_{1} \mathrm{OV}_{2}$ e $\mathrm{SOV}_{2} \mathrm{~V}_{1}$ não são possíveis. Embora Endruschat liste a opção OSV como existente na língua, exemplificando com a oração "Uma casa, o meu pai comprou." (Endruschat, 2006, p. 119), trata-se de uma estrutura não muito comum e de caráter oral. Ademais, a vírgula indica que a frase não está na ordem direta; afinal, em português, vírgulas não separam sujeito de predicado ou verbo de objeto. No caso de frases subordinadas, não há na língua portuguesa conjunções que exijam o deslocamento do verbo para o final da frase.

A questão central no que tange a estrutura alemã é como o intérprete será capaz de prever o verbo que será enunciado no final da frase, a fim de formular sua tradução em português sem longas pausas ou hesitações. E é exatamente aqui que surgem as colocações como uma estratégia de antecipação. 
Cabe acrescentar que, no esquema gráfico apresentado anteriormente, a base da colocação encontra-se dentro do retângulo, em geral logo em sua extremidade esquerda, enquanto o colocador (verbo) fica no fim da frase. Se o intérprete sabe que o verbo que acompanha a base Freundschaft ("amizade") é schließen ("fechar" em alemão, "fazer" ou "construir" em português), ele sabe que é esse o verbo que será enunciado no fim da frase, podendo então formular seu enunciado em português sem problemas.

Exemplo:

1) Heute haben wir eine schöne Freundschaft mit Frankreich geschlossen. ("Hoje fizemos/construímos uma bela amizade com a França.")

\subsection{Alemão como língua-fonte}

Muitos estudiosos da área da interpretação, dentre eles Gile (1995), defendem que fatores linguísticos, como diferenças sintáticas entre a língua-fonte e a língua-alvo, exigem do intérprete abordagens diferentes de recepção do enunciado e produção da mensagem. Consequentemente, é necessário o emprego de táticas específicas para cada combinação de línguas.

Valentina Donato publicou em 2003 um estudo cujo objetivo era investigar exatamente essa questão. Ela verificou se estudantes de interpretação recorrem a diferentes estratégias interpretativas conforme a língua-fonte a ser interpretada. Em seu trabalho foram comparadas interpretações entre os pares de língua inglês-italiano e alemão-italiano (Donato, 2003, p. 101).

$\mathrm{O}$ estudo de Donato demonstrou que o grupo de intérpretes que trabalhou do alemão para o italiano lançou mão de um número significativamente mais elevado de antecipações do que o grupo que trabalhou com o inglês. Esses resultados corroboram a teoria de que a antecipação é uma das principais estratégias empregadas na interpretação de alemão como língua-fonte.

De fato, a estrutura sintática da língua alemã, com o verbo principal em construções verbais compostas apresentando-se somente no fim da 
frase, oferece obstáculos bastante complexos no que diz respeito à sua interpretação para línguas latinas, como o francês, o espanhol, o italiano e o português, ao passo que o inglês apresenta uma estrutura mais semelhante a esses idiomas. O intérprete se vê, dessa forma, diante da necessidade de antecipar o verbo a ser proferido, a fim de poder dar continuidade à frase na língua-alvo, sem hesitar ou precisar ouvir o fim da frase para somente então começar a interpretar.

Infelizmente não foi encontrada em trabalhos acadêmicos uma relação das colocações mais recorrentes da língua alemã. Mas a autora deste artigo criou uma pequena lista de colocações típicas a partir de textos de revistas e jornais, reproduzida abaixo:

Alemão

Português

\begin{tabular}{|l|l|}
\hline Willkommen heissen & Dar as boas-vindas \\
\hline Eine Lehre ziehen & Tirar uma lição \\
\hline Eine Entscheidung treffen & Tomar uma decisão \\
\hline In Betracht ziehen & Ter em conta \\
\hline Weichen stellen & Definir rumos \\
\hline Druck ausüben & Exercer pressão \\
\hline Eine Frage stellen & Fazer uma pergunta \\
\hline Kontakt aufnehmen/knüpfen & Entrar em contato/travar contato \\
\hline Schritt tun/machen & Dar um passo \\
\hline Eine Rolle spielen & Desempenhar um papel \\
\hline Zu Ende gehen & Chegar ao fim \\
\hline Konflikte auftreten & Surgir conflitos \\
\hline Eine Liste erstellen & Criar uma lista \\
\hline Den Hunger ausmerzen & Erradicar a fome \\
\hline Das Risiko eingehen & Correr o risco \\
\hline Gefahr laufen & Correr perigo \\
\hline Zu dem Schluss kommen & Chegar à conclusão \\
\hline Abschied nehmen & Despedir-se \\
\hline Sich Gedanken machen & Pensar, refletir \\
\hline
\end{tabular}




\begin{tabular}{|c|l|}
\hline Sich Hoffnungen machen & Ter esperanças \\
\hline Kritik üben & Fazer críticas \\
\hline Rücksicht nehmen & Ter consideração \\
\hline Stellung nehmen & Tomar posição \\
\hline Wert legen & Dar valor a \\
\hline Die Verantwortung übernehmen & Assumir a responsabilidade \\
\hline Gute Arbeit leisten & Realizar um bom trabalho \\
\hline Leistung erbringen & Prestar serviço \\
\hline Sich Mühe geben & Esforçar-se \\
\hline Jemanden durcheinander bringen & Confundir alguém \\
\hline Mord begehen & Cometer um assassinato \\
\hline Kräfte bündeln & Unir esforços \\
\hline Einer Einladung folgen & Aceitar um convite \\
\hline Freundschaft schliessen & Fazer amizade \\
\hline In Kauf nehmen & Aceitar/sujeitar-se a \\
\hline Geschichte schreiben & Fazer história \\
\hline
\end{tabular}

\section{Considerações finais}

O objetivo deste trabalho foi apresentar a importância da estratégia da antecipação na interpretação simultânea alemão > português a partir das colocações definidas por Hausmann. Estas podem auxiliar o intérprete a contornar o problema da diferença entre a rigidez sintática do alemão e a flexbilidade do português, possibilitando um desempenho interpretativo mais seguro, assim como uma prestação mais fluente, e reduzindo a decalagem e o esforço mental de memorização por parte do intérprete. Ao conhecer a base, que é um dos elementos da colocação, ele pode prever seu colocador, ou seja, o verbo que vem ao final da frase e formular o enunciado em português antes mesmo de ouvir o enunciado completo.

Constatou-se ainda que os estudos das colocações na língua portuguesa ainda se encontram numa fase muito inicial, embora estejam bastante avançados em outros idiomas. Consequentemente, há poucos materiais publicados tratando especificamente do par de línguas alemãoportuguês. 
Como esta foi apenas uma primeira incursão no estudo dessa área em língua portuguesa, sugere-se que outros trabalhos deem continuidade a esta temática. Sugestões de estudo seriam: a) fazer uma análise de corpus de colocações recorrentes tanto em alemão quanto em português, b) analisar o papel das colocações na interpretação simultânea na direção oposta, ou seja, do português para o alemão, c) analisar o papel das colocações da língua portuguesa dentro do contexto de registro linguístico.

\section{Referências}

DONATO, Valentina. Strategies adopted by Student Interpreters in SI: A Comparison between the English-Italian and the German-Italian Languagepairs. In: The Interpreters Newsletter, $N^{\circ} .12,2003$.

ENDRUSCHAT, Annette. Einführung in die portugiesische Sprachwissenschaft. Tübingen: Narr Francke Attempto Verlag, 2006.

FRANCO, António. A Gramática de valências como modelo para a contrastação alemão-português: a ordem das palavras na frase alemã e portuguesa à luz desta gramática. Porto: Universidade do Porto. Disponível em: <http://ler.letras.up.pt/uploads/ficheiros/artigo5951.pdf> Acesso em março de 2011.

GILE, Daniel. Basic Concepts and Models for Interpreter and Translator Training. Amsterdã/Filadélfia: John Benjamins Publishing Company, 1995. GRAUER, Christian. Lesen, Verstehen und Übersetzen: Kollokationen als Handlungseinheiten der Übersetzungspraxis. Trier: WVT Wissenschaftlicher Verlag, 2009.

HAUSMANN, Franz-Josef. "Kollokationen im Deutschen Wörterbuch: Ein Beitrag zur Theorie des lexikographischen Beispiels", in Bergenholtz, H. \& Mugdan, J. (ed.): Lexikographie und Grammatik: Akten des Essener Kolloquiums zur Grammatik im Wörterbuch. Tübingen: Niemeyer, 1985. HOLDERBAUM, Anja. Kollokationen als Problemgrößen der Sprachmittlung. Trier: CD-ROM, 2003.

KALINA, Sylvia. Strategische Prozesse beim Dolmetschen: theoretische Grundlagen, empirische Fallstudien, didaktische Konsequenzen. Tübingen: Narr, 1998. 
MOHR, Roland. Empirische, korpusgestützte Untersuchung zu Strategien der Verarbeitung von Formen des gebundenen Sprachgebrauchs im Dolmetschprozess. Trier: WVT Wissenschaftlicher Verlag, 2009.

PÖLL, Bernhard. Portugiesische Kollokationen im Wörterbuch: Ein Beitrag zur Lexikographie und Metalexikographie. Bonn: Romanistischer Verlag, 1996.

RALL, M., ENGEL, U. \& RALL, D. Dependenz-Verb-Grammatik für Deutsche als Fremdsprache. Heidelberg: Julius Groos Verlag, 1985. SÁNCHEZ MARTÍNEZ, José Antonio. Barbara Moser: Simultaneous Interpretation: A Hypothetical Model and its Practical Application Versuch einer kritischen Auseinandersetzung. Eine theoretische Diskussion der Vorgänge beim Simultandolmetschen an Hand eines Modells. Mit Beispielen aus Verdolmetschungen vom Deutschen ins Spanische. Heidelberg: tese de Doutorado, 1988.

WÖRRLEIN, Marion. Der Simultandolmetschprozess. München: Martin Meidenbauer Verlag, 2007.

\section{Resumo}

O objetivo deste trabalho é apresentar um estudo em língua portuguesa sobre a importância das colocações, tal como definidas por Hausmann, no processo de interpretação simultânea alemão > português. Como os dois idiomas apresentam estruturas gramaticais bem diferentes entre si, o intérprete tem de saber lidar rapidamente com eventuais impasses daí decorrentes. Uma estratégia muito utilizada é prever o verbo que será enunciado no fim da frase em alemão, a fim de elaborar em português uma frase gramaticalmente correta e fluente, sem precisar de uma decalagem muito longa.

Palavras-chave: Interpretação simultânea alemão/português; colocações; estratégia de antecipação.

\footnotetext{
Abstract

This article aims to present a study in Portuguese on the importance of collocations as described by Hausmann in the process of interpreting simultaneously from German into Portuguese. Since these languages differ
} 
in their grammar structures, the interpreter has to be able to deal with possible stalemates resulting from such differences. A strategy very often applied is to anticipate the verb that will be uttered at the end of the sentence in German, in order to elaborate a fluent and grammatically correct sentence in Portuguese, without resorting to a very long decalage. Keywords: German/Portuguese simultaneous interpreting; collocations; anticipation strategy. 